\title{
Analysis of a planar manipulator operated by impulsion forces
}

\author{
Análisis de un manipulador plano operado mediante fuerzas de impulsión \\ Edgar A. Grisales V. ${ }^{1} \quad$ Héctor F. Quintero R. ${ }^{2} \quad$ Mauricio Monroy J. $^{2}$ \\ Recibido 28 de julio de 2014, aceptado 12 de mayo de 2015 \\ Received: July 28, 2014 Accepted: May 12, 2015
}

\begin{abstract}
For industrial automation it is often necessary to sort a large number of objects in a certain order for a subsequent step of process._Today, this is made by combining several pick and place robots, which move the objects to their desired destination one at a time. For a large number of objects per unit of time, this solution may become impractical because the individual robots may interfere with each other and the accelerations caused may be too high. This paper describes the principle of operation of a vibratory manipulator that produces impulsion force vector fields generated by longitudinal and transverse oscillations about a horizontal plane, which allow both movements of transport and orientation of parts. The manipulator has a rigid moving plate on which the object to move is placed. Then, forces on the moving plate are induced by longitudinal mechanical vibrations with asymmetric velocity profiles. Eight electromagnetic actuators that, in conjunction with flexible couplings, transmit longitudinal oscillations to the moving plate generate these velocity profiles. The amplitude of motion for each actuator is programmed by the user depending on the trajectory that the piece shall follow.
\end{abstract}

Keywords: Parallel manipulator, transport of parts, orientation of parts, mechanical vibrations, impulsion force.

\section{RESUMEN}

En la automatización industrial es frecuentemente necesario ubicar una gran cantidad de objetos en un determinado orden para un paso de proceso subsecuente. Actualmente, esto se lleva a cabo al combinar varios robots de tipo agarrar y ubicar, los cuales mueven los objetos a la posición deseada uno a la vez. Para gran cantidad de objetos por unidad de tiempo, esta solución puede tornarse impráctica porque los robots individuales pueden interferirse entre si y las aceleraciones causadas pueden ser muy altas. En este trabajo se describe el principio de operación de un manipulador vibratorio que produce campos vectoriales de fuerza de impulsión generados por oscilaciones longitudinales y transversales sobre un plano horizontal, las cuales permiten movimientos de transporte y orientación de piezas. El manipulador posee una placa móvil rígida sobre la que se ubica el objeto a mover. Luego, se inducen fuerzas en la placa móvil mediante vibraciones mecánicas longitudinales con perfiles de velocidad asimétrica. Estos perfiles de velocidades son generados mediante ocho actuadores electromagnéticos los cuales, junto con acoples flexibles, transmiten oscilaciones longitudinales a la placa móvil. La amplitud de movimiento de cada actuador es programada por el usuario en función de la trayectoria a seguir por la pieza.

Palabras clave: Manipulador paralelo, transporte de partes, orientación de partes, vibraciones mecánicas, fuerzas de impulsión.

\footnotetext{
1 Súper de Alimentos. Manizales, Colombia, E-mail: alexgrisales@gmail.com

2 Facultad de Ingeniería Mecánica. Universidad Tecnológica de Pereira. Pereira, Colombia. E-mail: hquinte@utp.edu.co; mauriciomonroy@utp.edu.co
} 


\section{INTRODUCTION}

Load handling equipment is used for movement and positioning of packaged goods, industrial and commercial components and finished products. These equipments can be used for mail processing or parts transport in manufacturing cells. Among conventional load handling equipment are the conveyor belts, and robotic manipulators. Conveyor belts are used to move large objects over long distances, but they lack the ability to move objects in multiple directions or orienting objects independently. Robots can accurately select, position, locate and orient pieces but also are limited by load capacity, reach and unhindered workspaces. In food and pharmaceutical industries, the handling of food and drugs must be done with clean surfaces and the use of robotic manipulators should be avoided due to its complexity of cleaning and disinfection. Manipulators are preferably applied in manipulation of other kinds of parts where movements are more related to automate processes needed, for example selection, orientation, placing and transport. This continuous flow of technology also serves to classify or segregate the materials by their size or weight using the vibration.

In the automation of manufacturing processes, feeding and orientation of parts are relevant tasks. These tasks are solved by dynamic processes caused by different kinds of forces like gravity, vibrations, air jets, magnetic fields and taps [1].

For automated assembly processes, pieces can be oriented while they are fed to the machine. There are several methods to manipulate parts for manufacturing. Some pieces can be oriented using force vector fields along a transversely vibrating surface [2]. Other methods require vibrations and mechanic filters along the path to achieve the correct orientation [3].

In [4], the authors bring a concept of transporting objects, based on the oscillations of a segmented planar surface. A segmented surface with individual drivers allows it to orient the parts individually, differencing this technology from the classical vibrating plate conveyors for bulk handling. On this surface, multiple objects can be manipulated simultaneously and independently with oscillations caused only to the portion of surface that lies beneath the part. These vibrations are controlled with a closed-loop system with computer vision, thus each piece can individually follow an arbitrary path, previously scheduled. For this manipulator, two main problems must be solved: i) To avoid the collision of adjacent surface elements due to their horizontal motion; this can be done by either having sufficient distance between elements or by synchronizing their motion, ii) the support and actuation of the surface elements becomes complicated if every element is allowed to have its own set of parameters.

The conveying process for micro parts based on the micro slide principle is simulated in [5] through the use of a multi-body model of a vibratory conveyor. To validate the simulation results, a vibratory conveyor consisting of three independent oscillation levels arranged on top of each other was developed by the authors. The conveyor allows the positioning and orientation of parts by adjusting the magnitude and phase of the oscillations.

In [6], parts are oriented along a squeeze line on a vibrating plate. In that example, however, the plate is flexible, and the sink line is a node of the vibration. Parts interact with the plate by microimpacts. In [7] by vibrating a rigid plate with up to six degrees of freedom, the authors create a large family of programmable frictional force fields acting on parts resting on the plate. These fields can be used for sensorless part orientation, uncertainty-reducing transport, and simultaneous manipulation of multiple parts.

The modeling, design and control of a 6-DOF parallel manipulator consisting of a rigid plate connected to linear actuators by flexure joints is shown in [8]. The manipulator controls the motion of parts on the plate's surface through programmable vibrationinduced sliding.

Using a massive amount of parallel arrays of actuators has also created programmable planar force fields. These actuators include MEMS devices [10], air jets [11], rolling wheels [12-14], and individual vibrating plates [6]. In this last system, each individual plate describes a circular motion in the horizontal plane and sinusoidal oscillations in the vertical direction. The phase difference of these motions determines the force felt by the parts on the plate, the net force is in the horizontal direction and the plate is moving 
when the effective gravity is greater. In [15] the friction forces are used to move objects along a planar horizontal surface by vibrating the surface with two degrees of freedom.

In [16], a two-way vibratory conveyor with the possibility of changing the direction of the transported material, by means of changing the excitation frequency of the vibrator, is analyzed.

In [17], a material handling system is developed using several small simple actuators cooperating to move large objects along a plane. A discrete set of cells, each comprising two actuators, are fixed in a planar array. By coordinating the actuators in the cells on which an object rests, this element can be displaced and oriented. This system is an improvement over traditional conveyor systems where objects can be re-oriented, as well as transported. Such an array provides flexible materials handling in which many objects can be manipulated and transported independently at the same time. The array is coordinated in a distributed manner where each cell has its own controller and each controller communicates with its neighbours.

In [18] the author developed a device which consists of a rigid plane powered by four linear actuators (voice coil actuator VCA), to generate asymmetric longitudinal vibrations in a two dimensional plane, thus creating driving force vector fields to manipulate objects that lie on that plate. In this paper, the handling is specially considered, by controlling simultaneously the position of one or more parts over a region bounded by the plane. Coulomb friction forces achieve the movement of the parts on the plane.

A method to create vibration patterns by means of an array of actuators acting on the boundaries of a controlled structure is shown in [19]. The method builds a black-box model by using a series of probing external excitation vectors. The paper describes the force-turning process through which several actuators can be modified automatically until the response measured in different locations matches with the anticipated response.

Periodic solutions for a class of micro robots operating based on friction drive were obtained in [20], by using an iteration perturbation method.
Locomotion in these micro robots was founded on the superposition of two synchronized perpendicular vibrations at the frictional interface of the robot and the work floor.

In the present work, an alternative for parts manipulation is presented according to several needs presented in industrial automated processes, for example, selection, orientation, placing and transport of parts. This is done by means of developing a manipulator, based on the Universal Planar Manipulator [18], using inexpensive and powerful actuators, scalable for applications with larger pieces at lower costs compared to the VCA alternative.

The manipulator consists of a flat square surface, actuated by solenoids driven by PWM signals, generated by an electronic circuit, which is controlled by a personal computer by means of a signal acquisition card. The control software is done with LabView.

The manipulator has a total of 8 solenoids, and is arranged as shown in Figure 1. This layout is needed to provide movement with 3-DOF.

To generate translation along two independent axes, it is required a minimum of two perpendicular double-effect linear actuators.

In order to generate rotation along an axis perpendicular to the plate, two opposed parallel forces are needed, i.e. a torque. Using one doubleeffect rotary actuator or two-paralleled double-effect linear actuators could do this.

Those two previous considerations give a minimum of 3 or 4 double-effect actuators.

In the case of the present work, the actuators selected are linear and can exert pulling forces only. Thus, for this manipulator, rotation motion is produced by means of activate simultaneously 4 solenoids 1, 4, 6 and 7 for clockwise rotation; and other 4 solenoids 2, 3, 5 and 8 for the counterclockwise case. That makes a total of 8 solenoids.

This layout also allows exerting twice the torque than the case of activate, for example, solenoids 1 and 4 only. 
The translation movements are produced by means of activate two solenoids at the same time: 1 and 2 for $\mathrm{Y}(+)$ motion, 3 and 4 for $\mathrm{Y}(-), 5$ and 6 for $\mathrm{X}(-)$ and 7,8 for $\mathrm{X}(+)$ motion.

This layout and mode of activation is also necessary to produce a straight linear motion.

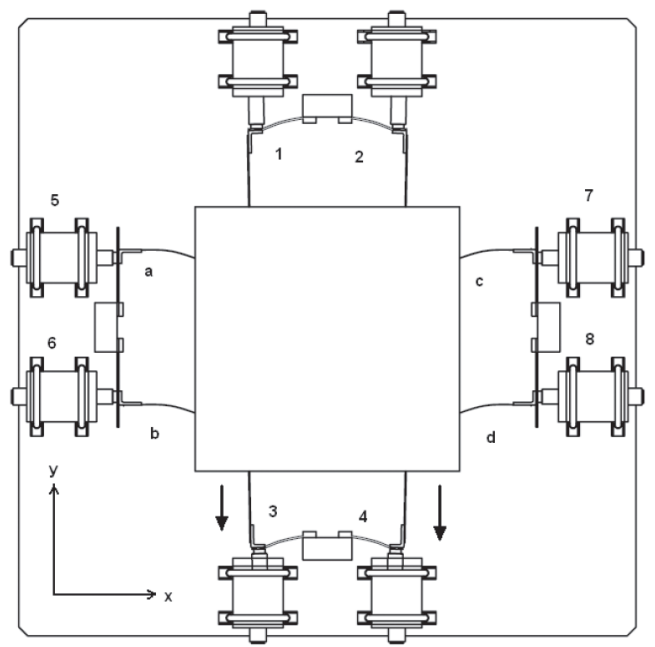

Figure 1. Manipulator layout.

This technology competes not only with robots, which are applied for discrete flow of items, but other continuous flow handling methods. Continuous flow methods such as belt conveyors and screw conveyors lack the ability to orient parts individually, although they can set a mean direction for the velocity vector field for the case of flow in bulk.

\section{OPERATING PRINCIPLE}

Figure 2 shows the analysis of manipulation of parts on a vibratory surface with three degrees of freedom. The dotted square represents the plane $S$ in the initial position, with the midpoint in the origin O; the solid line square represents the plane $S$ with translation $\mathrm{O}_{\mathrm{S}}$ and rotation $\theta_{\mathrm{S}}$. The piece to move is represented by a mass point $P$.

The vibrating surface is restricted to move with three degrees of freedom along $X Y$ plane. The system $\mathrm{O}_{\mathrm{S}}$ $=\left(\mathrm{X}_{\mathrm{S}}, \mathrm{Y}_{\mathrm{S}}\right)$ denotes displacement, and $\theta_{\mathrm{S}}$ denotes the rotation of the surface. Surface movement is considered smooth and periodic, where $S(0)=$ $S(T)$. For a period $T>0$, the tangential velocity $v_{\mathrm{S}}$ at point $P$ is:

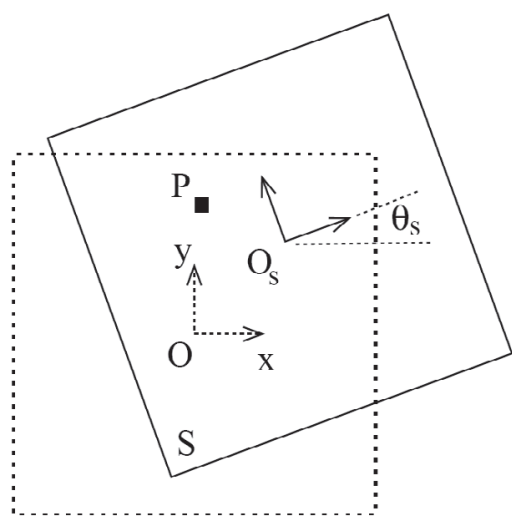

Figure 2. Movement along the surface.

$$
v_{S}(P, T)=\dot{O}_{S}(t)+\dot{\theta}_{S} \times\left(P-O_{S}(t)\right)
$$

$P$ is considered as a point mass, which rests on surface $S$. Naming $v_{\mathrm{S}}$ and $v_{\mathrm{P}}$, as instantaneous velocities of the surface and the piece respectively; the following cases can be formulated:

1. Piece $P$ always slips on surface $S$. The relative acceleration of $P$ causes inertial forces greater than the threshold of static friction, for every $t \in[0, T)$. Dynamic Coulomb friction force $f_{\mathrm{D}}$ is constant in magnitude $\mu \cdot \mathrm{m} \cdot \mathrm{g}$ and opposed to relative motion of the piece and the surface.

$$
f_{D}=\mu m g \frac{v_{S}-v_{P}}{\left\|v_{S}-v_{P}\right\|}
$$

If the speed of the part $v_{\mathrm{P}}(t)$ is negligible compared with $v_{\mathrm{S}}(P, t)$, equation (2) reduces to:

$$
f_{D}=\mu m g \frac{v_{P}(P, t)}{\left\|v_{P}(P, t)\right\|}
$$

2. Piece $P$ always sticks to the surface. In this case, the velocities of the piece and the surface are equal $v_{\mathrm{S}}=v_{\mathrm{P}}$. Surface moves with an acceleration $a_{\mathrm{S}}(P)$ $\in\left[-a_{\mathrm{S}}, a_{\mathrm{S}}\right]$. Then $a_{\mathrm{P}}(t)=a_{\mathrm{S}}(P, t)$. This happens when parts have high friction coefficients, for example rubber pieces.

3. Piece $P$ is moved over the surface. The movement of the surface is divided in two phases (asymmetric velocity profile). In phase 1 the piece sticks to the surface, then $a_{\mathrm{P}}(t)=a_{\mathrm{S}}(P, t)$, and $v_{\mathrm{P}}(t)=v_{\mathrm{S}}(P, t)$. 
In phase 2, the piece slides forwards the surface, when this one accelerates backwards with a velocity greater than the one in stage 1.

Figure 3 shows the mechanical model of an eighth of the manipulator and its components. Surface $S$ supports the piece $\mathrm{P}$, the solenoid draws a longitudinal force $f_{\text {ext }}$ to the surface; $k$ and $b$ represent the equivalent elasticity and damping coefficients for the couplings.

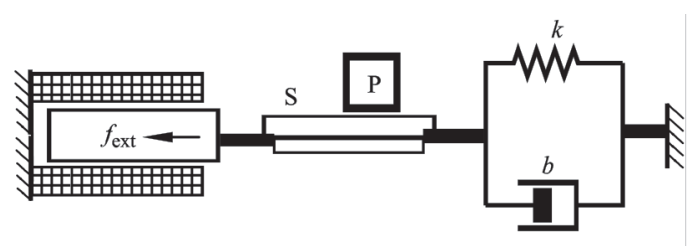

Figure 3. Mechanical model.

The surface $S$ is a rigid moving plate on which piece $\mathrm{P}$ can be displaced or rotated. The plate is connected to 8 solenoids that generate programmable oscillations controlled by computer. A Joystick is used to interact with the user, to move the piece P.

The displacement of the object along the plate is obtained by controlling the velocity profile of the surface. To achieve the movement of the object, the velocity profile must be asymmetric. When velocities and accelerations of the surface and the piece are the same, the object moves together with the plate. If the acceleration of the plate $\mathrm{S}$ is greater than the acceleration of the piece $P$, the object slips over the surface.

The motion of the surface has two stages:

In stage 1, the piece P slips forwards with respect to the plate $\mathrm{S}$ when this one accelerates backwards; in the second stage, the velocities of $\mathrm{P}$ and $\mathrm{S}$ are equal, so the piece $(\mathrm{P})$ sticks to the surface. This way, one motion cycle occurs when the surface of the plate moves slowly forwards (piece sticks) and quickly moves backwards (piece slips).

When an excitation signal, which can be varied by means of pulse width modulation (PWM), is applied to the actuators, there are three possible conditions that depend on the waveform, acceleration and system dynamics:
1. Symmetric velocity, where the piece moves back and forth together with the surface.

2. Symmetric velocity, where the piece slips without motion of any kind.

3. Asymmetric velocity, where the piece moves in the direction of the lower speed of a cycle.

With the rigid planar manipulator proposed in this work, the three previously mentioned degrees of freedom, two of displacement and one of rotation, can be achieved. The positive longitudinal movement parallel to $\mathrm{X}$-axis, $\mathrm{X}(+)$, for the piece $\mathrm{P}$ over the plate $S$, shown in Figure 4, is obtained by energizing simultaneously solenoids 0 and 1 , exerting a compression force to the flexible couplings b0, b1, attached to these solenoids; b4, b5, attached to solenoids 4 and 5 (which are inactive in this case) and couplings a2, a3, a6, a7, which are orthogonal to the $\mathrm{x}$ axis.

Figure 4 also shows the configuration when, by activating solenoids 0 and 1 , force fields are generated along $\mathrm{X}(+)$. With this arrangement, the movement $\mathrm{X}(+)$ is applied to the piece. Additionally, solenoids 2, 3, 6 and 7 are also inactive to get straight-line motion.

The motion of the piece in the negative direction $\mathrm{X}(-)$, is done by actuating the solenoids 4 and 5 in a similar manner, leaving inactive solenoids 0 and 1 .

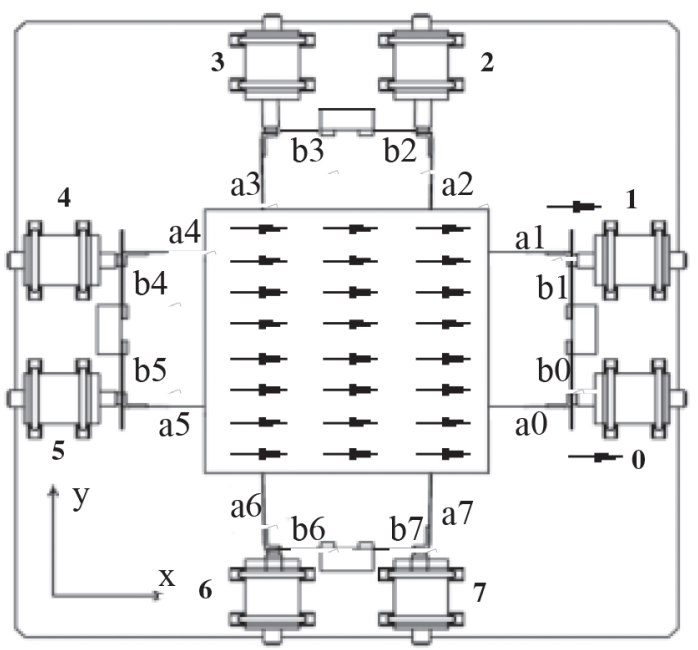

Figure 4. Arrangement of the 8 solenoids, $X+$. 
When solenoids 6 y 7 are simultaneously actuated, as seen in Figure 5, the surface is displaced along $\mathrm{Y}$ axis, in direction $Y(-)$, the couplings a0, a1, a4 and a5 are bent (storing energy), the arrays 6 and 7 pull the plate and at the same time, the plate pulls the couplings b2 and b3. The flexible couplings mentioned bend to displace the surface in the direction of the force field.

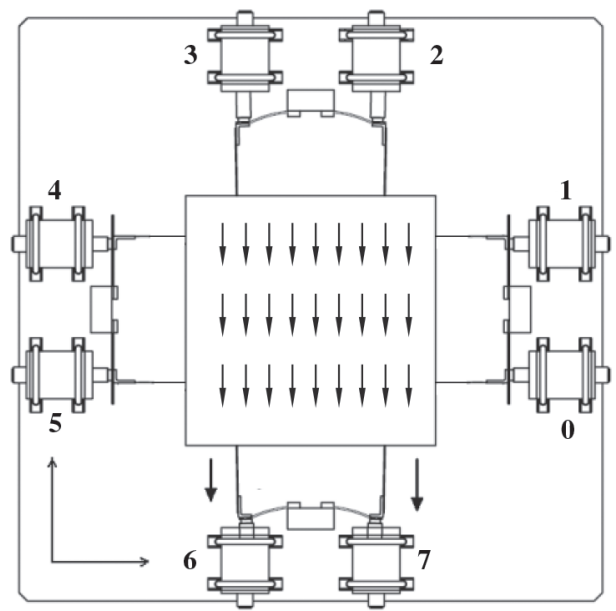

Figure 5. Longitudinal movement, Y-.

When solenoids 6 and 7 are switched off, the energy stored in couplings a0, a1, a4, a5 is released, so the plate returns to its original position. The couplings $\mathrm{a} 2$ and $\mathrm{a} 3$ push the plate, so these couplings are submitted to compression forces that flex them, thus dissipating a part of the energy. This does not happen with couplings a 6 and a7 because these are submitted to tension.

For a combined motion in the $\mathrm{X}$ and $\mathrm{Y}$ axes, as seen in Figure 6, electromagnets 0, 1, 2 and 3 are activated, which generates an impulsion vector force field, according to the command signals sent to these actuators.

Simultaneously the solenoids $0,2,4,6$, Activates counterclockwise rotation, as seen in Figure 7, done by The switching is done with PWM.

An accelerometer ADXL345 from Analog Devices is used to measure accelerations up to $\pm 16 \mathrm{~g}$. This is a design constraint for the selection of the frequency of operation and amplitude of movement of the manipulator's plate.

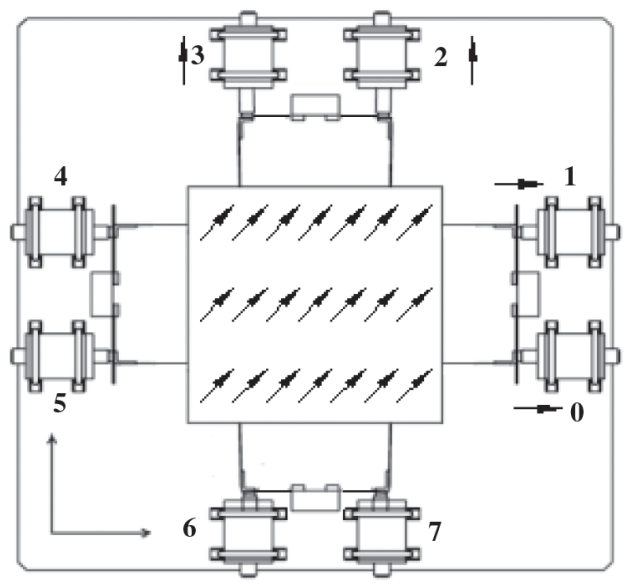

Figure 6. Translation movement X-Y.

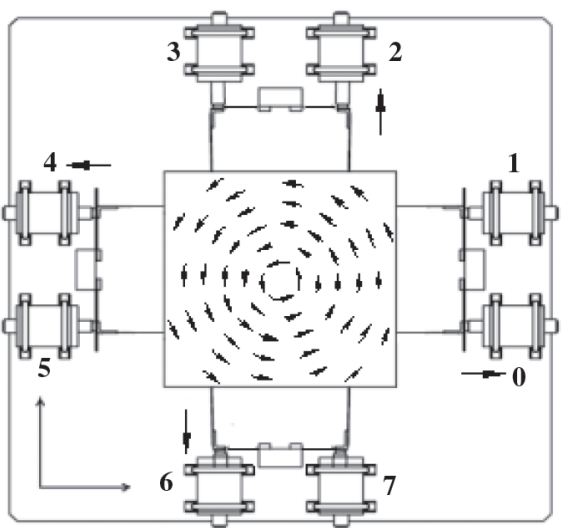

Figure 7. Rotational motion, counterclockwise.

Assuming that the oscillation is sinusoidal, the acceleration is estimated with equation (4), as presented in [21].

$$
a_{t}=\frac{2 N A_{t}}{70400}
$$

Where $a_{\mathrm{t}}$ is the maximum acceleration of the table along a horizontal line, expressed in $g(1 g=9,81$ $\left.\mathrm{m} / \mathrm{s}^{2}\right) ; \mathrm{N}$ is the operating frequency in cycles per minute; $A_{\mathrm{t}}$ is the amplitude of oscillation of the table, expressed in inches, and 70400 is a constant which comes from simplifications and unit conversions.

Table 1 shows the maximum acceleration values for the operation of the manipulator, for different frequencies and displacements.

These values shall never exceed $16 g$ for both the machine and accelerometer. 
Table 1. Accelerations as function of frequency and displacement

\begin{tabular}{|c|c|c|c|}
\hline$F[\mathrm{~Hz}]$ & $\begin{array}{c}A[g] \\
\mathrm{a} 1 \mathrm{~mm}\end{array}$ & $\begin{array}{c}A[g] \\
\mathrm{a} 1,5 \mathrm{~mm}\end{array}$ & $\begin{array}{c}A[g] \\
\mathrm{a} 2 \mathrm{~mm}\end{array}$ \\
\hline 30 & 1,81 & 2,72 & 3,62 \\
\hline 35 & 2,47 & 3,70 & 4,93 \\
\hline 40 & 3,22 & 4,83 & 6,44 \\
\hline 42 & 3,55 & 5,33 & 7,10 \\
\hline 45 & 4,08 & 6,12 & 8,15 \\
\hline 50 & 5,03 & 7,55 & 10,07 \\
\hline 55 & 6,09 & 7,55 & 12,18 \\
\hline 60 & 7,25 & 9,14 & 14,50 \\
\hline 63 & 7,99 & 10,87 & 15,98 \\
\hline 65 & 8,51 & 11,99 & - \\
\hline 70 & 9,86 & 12,76 & - \\
\hline 72 & 10,44 & 14,8 & - \\
\hline 75 & 11,32 & 15,65 & - \\
\hline 80 & 12,88 & - & - \\
\hline 85 & 14,55 & - & - \\
\hline 89 & 15,95 & - & - \\
\hline
\end{tabular}

The couplings are made to fulfill four main purposes:

1. To transmit traction forces exerted by the solenoids. The core of the electromagnets comes in the bobbin, so the plate moves pulled by the iron core.

2. To absorb small deformations caused by the motion of the solenoid plunger with respect to the spring.

3. To reduce possible transverse oscillations of the moving surface.

4. To subtract kinetic energy by means of the bending of the coupling when this one is submitted to compression during the switch-off stroke.

Calculations for dimensioning the coupling springs are performed to operate at the natural frequency of the mechanical system, with a resonance frequency at $45 \mathrm{~Hz}$, and a fatigue resistance for infinite lifespan less than $138 \mathrm{MPa}$ and a strip spring with 2,03 mm in width. The design of the spring is based on [22].

\section{SOLENOID CHARACTERISTICS}

Figure 8 presents the main parts of a tubular solenoid used for the manipulator. The moving plunger (core) 301 has a squared contact surface because this configuration is the most adequate for cores of less than 1,5 mm stroke. The coil 303 is wound

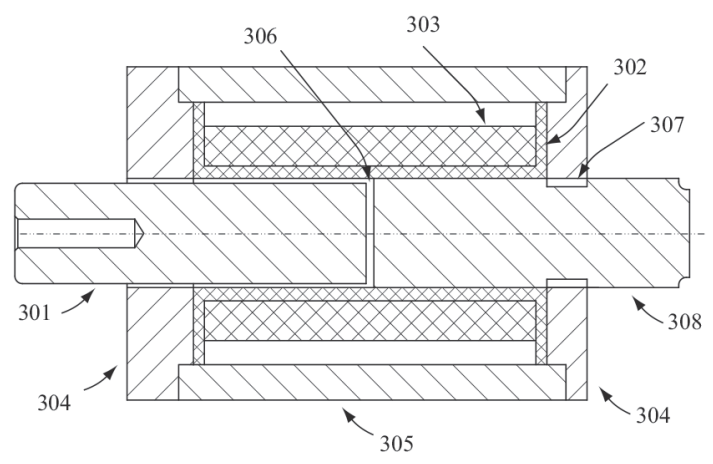

Figure 8. Tubular solenoid.

around a cylindrical reel 302. The covers 304 and the housing 305 conform the solenoid frame. The air gap 306 separates the plunger from the backstop 308. Threaded washer 307 adjusts the air gap. The solenoid is made of steel alloys with the magnetic properties required for the application. This type of solenoid is a linear electromagnetic actuator, with quick response and high strength for short strokes.

The specifications for the solenoid are given in Table 2.

Table 2. Specifications for the solenoid.

\begin{tabular}{|l|l|}
\hline Starting force & $F_{\mathrm{dp}}=9 \mathrm{kgf}$ \\
\hline Maximum air gap & $d=1,3 \mathrm{~mm}$, \\
\hline Duty cycle & (Intermittent) 50\%, \\
\hline Geometry & cylindrical \\
\hline Plunger material & SAE 1010 \\
\hline Magnetic flux density & $B_{\mathrm{S}} \cong 1,84$ Tesla \\
\hline Physical dimensions & \\
\hline Plunger diameter & $d=17 \mathrm{~mm}$ \\
\hline Outer diameter & $d_{\mathrm{be}}=45 \mathrm{~mm} ;$ \\
\hline Thickness & $t_{\mathrm{b}}=1 \mathrm{~mm}$ \\
\hline Length & $L_{\mathrm{c}}=60 \mathrm{~mm}$ \\
\hline gap & $1,3 \mathrm{~mm}$ \\
\hline Housing diameter & $48,1 \mathrm{~mm}$ \\
\hline Housing length & $72,42 \mathrm{~mm}$ \\
\hline Effective stroke & $3,1 \mathrm{~mm}$ \\
\hline Number of turns & $N=2500, \mathrm{AWG} 27$ \\
\hline Current density & $J=5,6 \mathrm{~A} / \mathrm{mm}^{2}$ \\
\hline Working current & $i_{\mathrm{P}}=0,56 \mathrm{~A}$ \\
\hline $\begin{array}{l}\text { Inductance at } 1,2 \mathrm{~mm} \\
\text { stroke }\end{array}$ & $1,49 \mathrm{H}$ \\
\hline
\end{tabular}

\section{CONTROLLER}

To control the operation of the manipulator, a signal data acquisition and drivers board was 
designed, where most of its tasks are concentrated in generating PWM control signals. The computer provides the values for duty cycle and frequency for each channel and handles the communications with the circuit board.

An additional driving hardware is selected in which eight PWM output drivers are physically implemented, one for each solenoid. All the PWM generators are embedded into one chip, since all output signals must be in phase. This solution is implemented in an evaluation cardboard that uses a 32-bit Stellaris LM3S3748 (ARM CORTEX M3 Core) microcontroller from Texas Instruments.

This data acquisition card is programmed in $\mathrm{C}$ language into the Coox CoIDE development environment. Its channels are used as follows:

Eight digital outputs are used as independent PWM channels to modulate the power to the electromagnets. A 16-bit base frequency is used for PWM generation. For each PWM channel, there is a resolution of 8 bits.

Of eight available digital inputs, some of them are used as Emergency stop, Pause, PWM reset.

A serial USB port is connected to the $\mathrm{PC}$ at a transfer rate of 921600 Baud. The LM3S3748 processor operates mostly in stand-alone mode in order to reduce USB traffic handling tasks.

Two serial SPI ports are used to connect with 2 ADXL345 accelerometer boards.

In Figure 9, a schematic diagram with the main components of the controller is shown.

Figure 10 shows the flowchart of the program of the acquisition card.

As the card has a chip with 8 embedded PWM signal generators, all these signals are in phase. The eight 8-bit registers associated with the desired PWM output values, P0 to P7, as well as the eight 8-bit registers containing the frequencies for each individual PWM channel, F0 to F7, are updated at the same time when the operation Update Data to Transmit is performed.

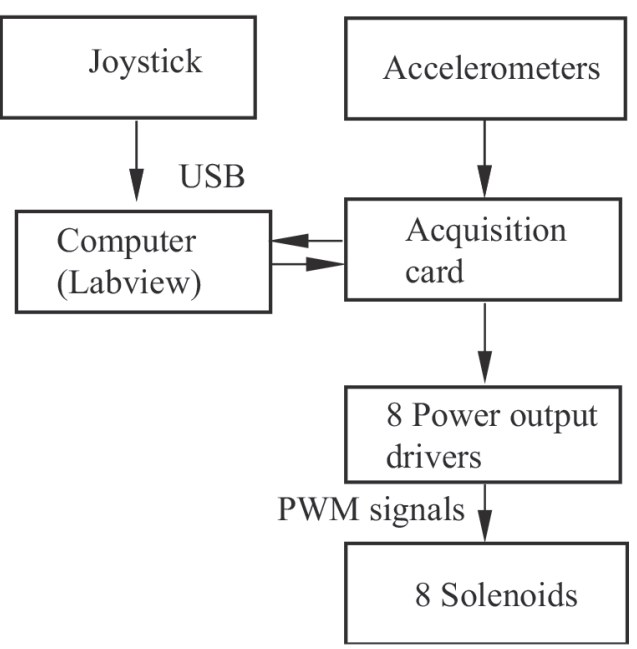

Figure 9. Schematic diagram of the control system.

When the card performs Transmit Accelerometers Data, the computer receives:

One 8-bit register for the status of digital inputs. One 16-bit register for the data of the $\mathrm{X}$ component of the accelerometer 1 .

One 16-bit register for the data of the $\mathrm{Y}$ component of the accelerometer 1 .

One 16-bit register for the data of the $\mathrm{X}$ component of the accelerometer 2 .

Finally, one 16-bit register for the data of the $\mathrm{Y}$ component of the accelerometer 2 .

Figure 11 shows the flowchart of the main program for the manipulator, which operates on the computer, under the National Instruments LabVIEW 2010 environment, using Toolkit Sound and Vibration Measurement Suite packages.

There are routines of initialization, a master cycle, a slave cycle and a parallel cycle in the main program.

In the initialization routine, a Joystick, a USB port and a circular buffer are con Figured.

The master cycle is used to receive the accelerometers' data (read VISA port). This data is concatenated and then saved in a circular buffer. 


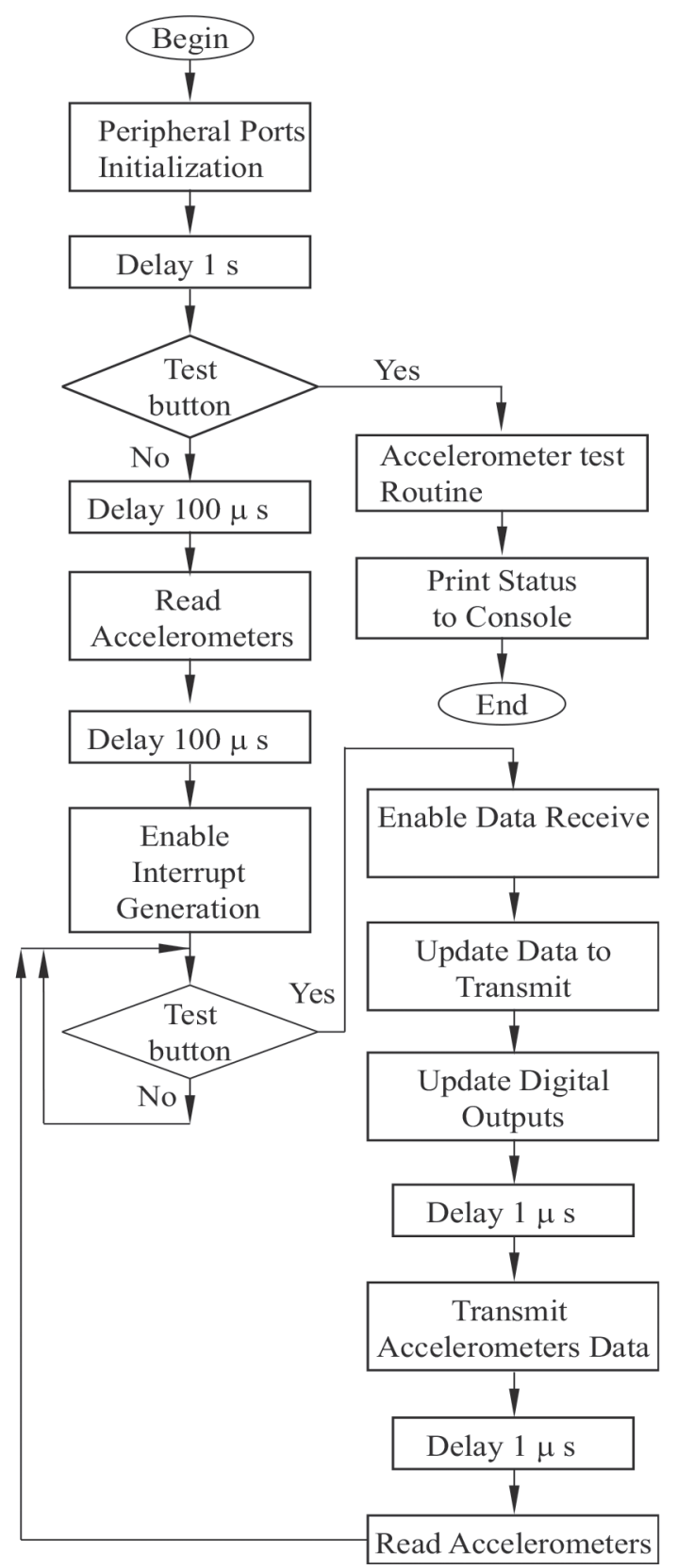

Figure 10. Flowchart of the acquisition card.

In the slave cycle, the accelerations obtained and its calculated integrals (velocities), saved in the buffer, are plotted into the screen. The program also allows plotting the magnitude of the Fast Fourier Transform (FFT), with a selected frequency spectrum.

In the parallel cycle, the Joystick data is read, and the program sends to the acquisition card

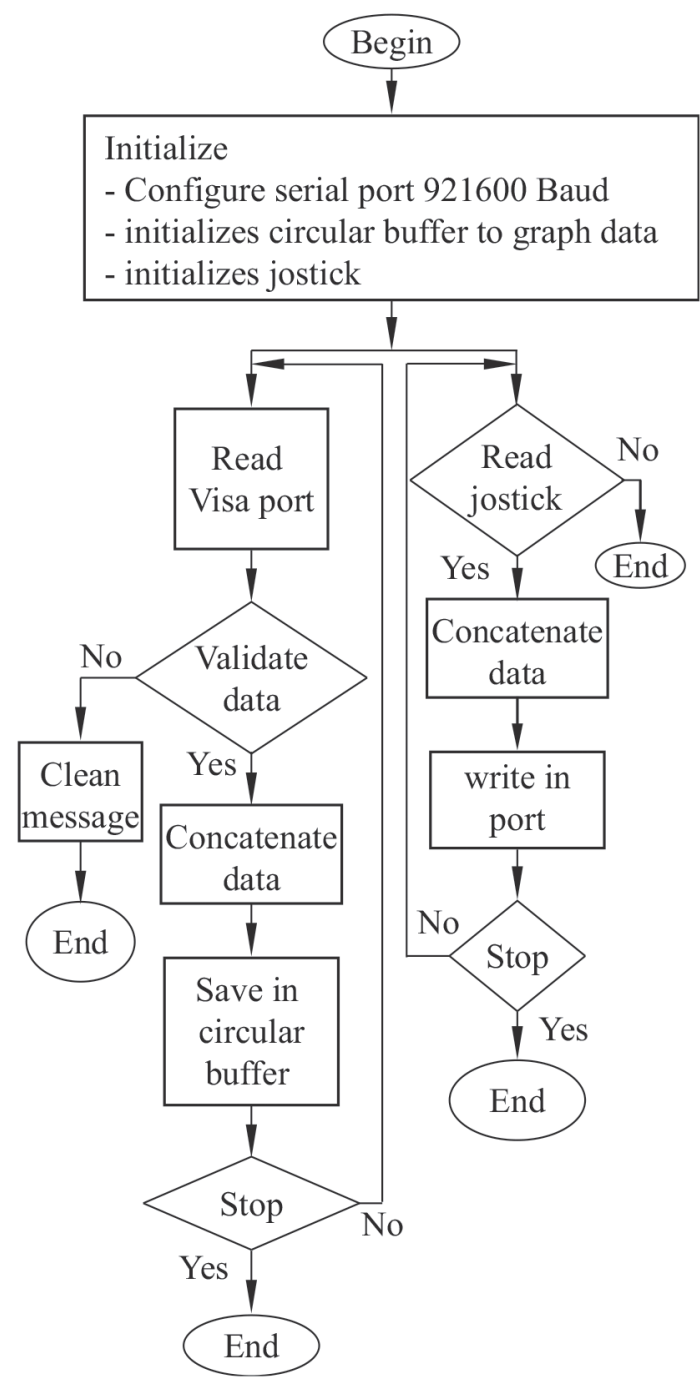

Figure 11. Flowchart of the main program.

the concatenated values of PWM output ratios and frequencies of operation for each of the 8 actuators.

It is also possible to manually set the values of PWM output ratio and frequency for each solenoid.

\section{OPERATIONAL TESTS}

Several motion tests are performed to validate the three degrees of mobility. These tests are made along $\mathrm{X}$ and $\mathrm{Y}$ axis, making both positive and negative displacement for each axis individually. Then, tests are made combining $\mathrm{X}$ and $\mathrm{Y}$ translation in straight line. 
Finally, rotational fields are induced to test the third degree of motion along the plane. A joystick Genius MaxFighter F-17 allows interaction with the user, as seen in Figure 12.

The tests are made with two white cylindrical pieces made of high-density polyethylene, which are 28 $\mathrm{mm}$ in diameter, $10 \mathrm{~mm}$ in height, and weigh 5,6 grams each. There is a static friction coefficient of 0,3 between the surface of the plate and the pieces (value obtained with inclined wedge method). The dimensions and weight of the objects are arbitrary, but the color was selected to have a contrast with the plate, which is black.

The air gap of the electromagnets is manually adjusted with the threaded nuts, and fine-tuning is performed with the help of the PC software, which is programmed in LabView.

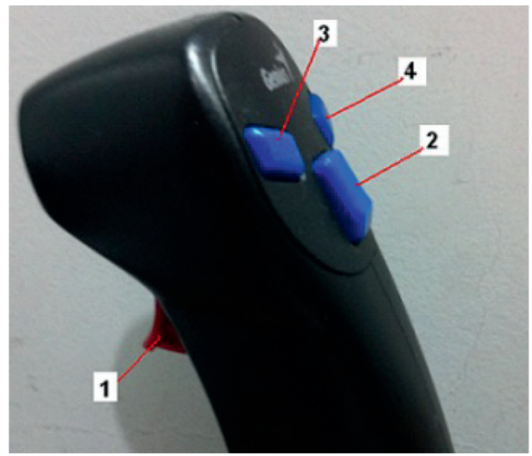

Figure 12. Joystick.

These adjustments are made in order to: set amplitude of vibration for maximum velocity (this is measured with the accelerometers), to avoid shock noises due to contact between backstop and plunger, and to reduce electrical consumption.

\section{Movement along $\mathrm{X}$ axis}

In Figure 13, the graphic interface of the manipulator is shown. The value entered in the "P0" box is the duty cycle between 0 and $100 \%$ that will be applied to solenoid 0 , the value in $\mathrm{P} 1$ corresponds to the duty cycle to apply to solenoid 1, and so on for P2, P3, P4, P5, $\mathrm{P} 6$, and $\mathrm{P} 7$. These values are for fine-tuning purposes.

The electromagnets 0 and 1 are energized at the same time with a $27,5 \%$ duty cycle, and a frequency of $30 \mathrm{~Hz}$. This frequency and duty cycle generate acceleration below the $16 \mathrm{~g}$ limit, as seen in Table 1 .

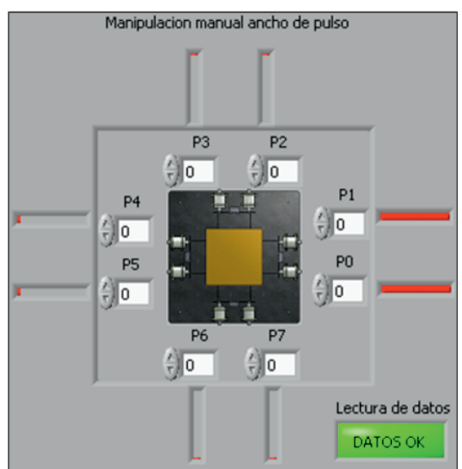

Figure 13. Graphic Interface, $\mathrm{X}+$.

The solid gray horizontal bars next to $\mathrm{P} 0$ and $\mathrm{P} 1$ represent the turning of the lever.

Figure 14 shows a sequence of stills 1-2-3-4$5-6$, captured with a webcam, during the $\mathrm{X}(+)$ manipulation. The pieces were displaced at an approximate speed of $19 \mathrm{~mm} / \mathrm{s}$.

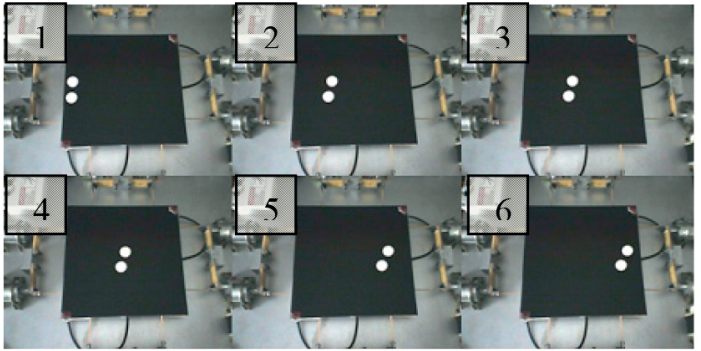

Figure 14. Motion along $\mathrm{X}$ axis.

\section{Movement along $\mathbf{Y}$ axis}

The joystick is moved forward to set motion in the $\mathrm{Y}(+)$ direction, then the electromagnets 2 and 3 are energized at the same time with a duty cycle of $27,5 \%$ and an excitation frequency of $30 \mathrm{~Hz}$. In the graphic interface, grayed bars above P2 and P3 represent the forward turning of the lever, similar to the case of the bars shown in the Figure 13.

Figure 15 shows a sequence of stills, captured with a webcam, during the $\mathrm{Y}(+)$ manipulation. The pieces were displaced at an approximate speed of $20 \mathrm{~mm} / \mathrm{s}$.

\section{X-Y Movement}

The joystick is moved to the right and forwards, the motion selected is $\mathrm{X}(+)$ and $\mathrm{Y}(+)$. The solenoids 0 , 1,2 and 3 are activated with $27,5 \%$ duty cycle and an excitation frequency of $30 \mathrm{~Hz}$. 


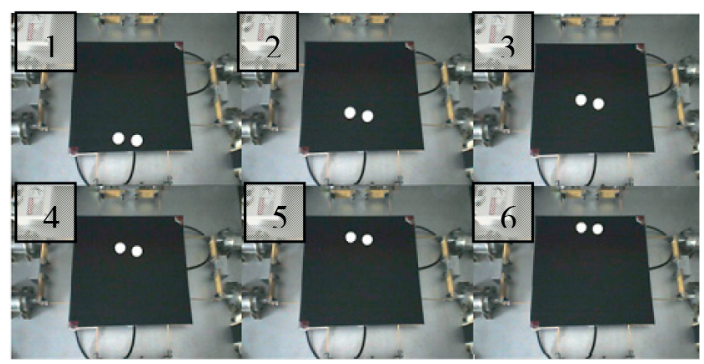

Figure 15. Motion along Y axis.

Figure 16 shows the graphic interface with the combined X-Y command represented in the bars next to $\mathrm{P} 0, \mathrm{P} 1, \mathrm{P} 2$, and $\mathrm{P} 3$.

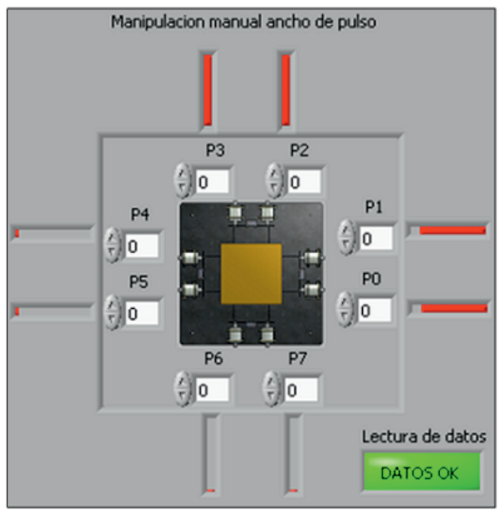

Figure 16. Graphic interface, X-Y motion.

Figure 17 shows a sequence of stills, captured with a webcam, during the combined motion. The pieces were displaced at an approximate speed of $23,8 \mathrm{~mm} / \mathrm{s}$.

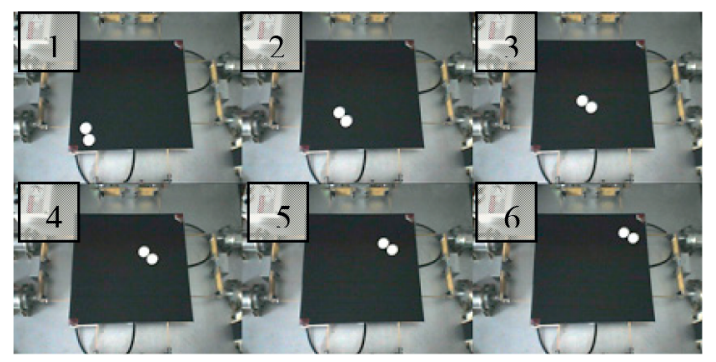

Figure 17. X-Y motion stills.

\section{Tests for rotational field generation}

By pressing the button " 2 " of the joystick (see Figure 12), the electromagnets $0,2,4,6$ are activated with a duty cycle of $27,5 \%$ and an excitation frequency of $30 \mathrm{~Hz}$, generating a rotational force vector field on the plate.

Figure 18 shows the representation on the graphic interface of the rotation command using the bars next to P0, P2, P4, and P6.

Figure 19 shows a sequence of 16 stills, captured with a webcam, during the rotation motion. The pieces were rotated at an approximate tangential speed of $23 \mathrm{~mm} / \mathrm{s}$. The pieces were aligned at an approximate radius of $100 \mathrm{~mm}$ respect to the center of the surface.

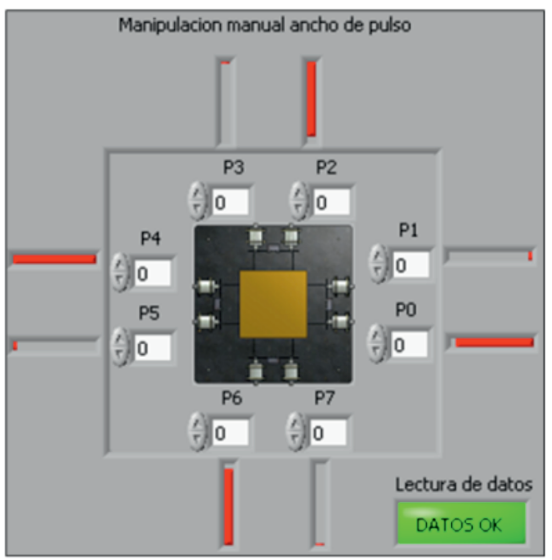

Figure 18. Graphic interface, Rotation.

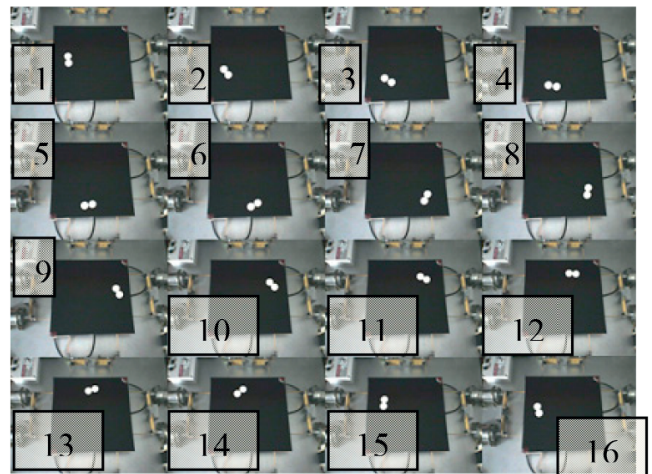

Figure 19. Rotational motion stills.

Tests were performed manipulating different pieces of various materials (wood, metal, plastics among others) following arbitrary paths on the surface, as seen in Figure 20. The transport rate of the pieces along the surface depends on the friction coefficient between surfaces. Because of this, the movement of rubber pieces is very slow. 


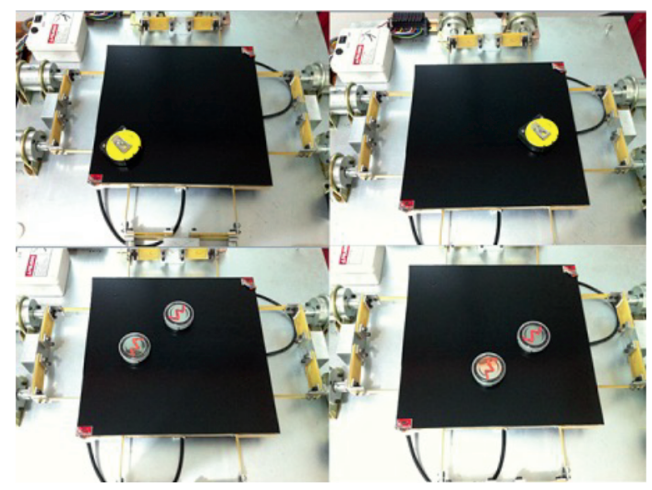

Figure 20. Manipulating several objects.

\section{CONCLUSIONS}

In this work is shown that a low-cost control system can be implemented for this manipulator by using a microcontroller, such as the Texas Instruments LM3S3748. The control software implemented allows, unlike other commercially available acquisition cards, dedicated generation of PWM signals and acceleration readings, with less communications traffic on the USB port and computer processing.

One of the features of the developed manipulator is the low cost of fabrication, as the cost of materials of the prototype goes around U\$ 1500 . In contrast, fabricating the manipulator with four Voice Coil Actuators, with a $50 \mathrm{Lbf}$ specification each, would be more costly, as U\$ 4800 would be needed just for the actuators.

The acting system can hold the structure of the manipulator very stable while generating force vector fields on the moving plate, thus producing reliable translation and rotation of objects on the plate. The plate is excited around resonant frequency to maximize the amplitude of vibration.

The motion generation with three independent degrees of freedom was tested and verified, performing movements of pieces following straight trajectories, back and forth, parallel to the axes, skewed, and also in a rotatory fashion by activating certain groups of solenoids.

By moving the joystick at the will of the user, objects can be manipulated following desired paths, thus demonstrating the utility of employing this manipulator into activities where a human being shouldn't or couldn't handle certain objects due to possible safety issues or health risks.

The operation of the manipulator depends on the friction coefficient between two surfaces, thus, it is required that a surface of the piece makes contact with the surface of the vibrating plate. This machine cannot operate with one point of contact, for example a spherical piece, nor a line of contact, for example a cone or cylinder.

\section{REFERENCES}

[1] G Boothroyd. "Assembly Automation and Product Design. Taylor and Francis Group. 2da edición, pp. 6-10. New York, USA. ISBN: 0-8247-8547-9 1991.

[2] K.F. Böhringer, R Donald and L.E. Kavraki. "Part orientation with one or two stable equilibria using programmable force fields". IEEE Transactions on robotics and automation. Vol. $16 \mathrm{~N}^{\circ} 2$, pp. 157-170. April, 2000. ISSN: 1552-3098.

[3] O.C Goemans and A.F Stappen. "On the design of traps for feeding 3D parts on vibratory tracks". IEEE Intern Conf on Robotics and Automation, Pasadena USA, pp. 385-392. May 19-23, 2008. DOI: 10.1109/ ROBOT.2008.4543238.

[4] P.U. Frei. "Theory, Design and Implementation of a Novel Vibratory Conveyor". Ph. D. Thesis. Swiss Federal Automated supply of micro parts based on the micro slide conveying principle Institute of Technology. Zurich. 2002.

[5] J. Flesicher, S. Herder and U. Leberle. CIRP Annals-Manufacturing Technology. Vol. 60, pp. 13-16. 2011.

[6] K. Böhringer, B.R. Donald, L.E. Kavraki and F. Lamiraux. "A Single Universal Force Field can Uniquely Orient non-Symetric Parts". Proc on the 9th Intern Symp Robotics Research ISSR 1999, pp. 313-320. Snowbird, USA. October, 1999.

[7] T.H. Vose, P. Umbanhowar and K.M. Linch. "Friction-Induced velocity fields for point parts sliding on a rigid Oscillated Plate". Intern Journal of Robotics Reseach. Vol. 28 $\mathrm{N}^{\mathrm{o}} 8$, pp. 1020-1039. August, 2009. ISBN: 0278-3649. 
[8] T.H. Vose, M.H. Turpin, P.M. Dames, P. Umbanhowar and K.M. Lynch. "Modeling, design, and control of 6-Dof flexurebased parallel mechanisms for vibratory manipulation". Mechanism and Machine Theory. Vol 64, pp. 111-130. 2013.

[9] T.H. Vose, P. Umbanhowar and K.M. Linch. "Friction-Induced Lines of Attraction and Repulsion for parts sliding on a oscillated plate". IEEE Transactions on Automation Science and Engineering. Vol. $6 \mathrm{~N}^{\circ} 4$, pp. 685-699. October, 2009. DOI: 10.1109/ TASE. 2009.2021360

[10] K.-F. Böhringer, B. Donald and N. MacDonald. "Sensorless manipulation using massively parallel microfabricated actuator arrays". IEEE International Conference on Robotics and Automation. 1994.

[11] S. Konoshi and H. Fujita. "A conveyance system using air flow based on the concept of distributed micro motion systems". Journal of Microelectromechanical Systems. Vol. 3 $\mathrm{N}^{\mathrm{o}}$ 2, pp. 54-58. 1994.

[12] J. Luntz, W. Messner and H. Choset. "Velocity field design for parcel manipulation on the modular distributed manipulator system". IEEE International Conference on Robotics and Automation. 1999.

[13] J.E. Luntz, W. Messner and H. Choset. "Distributed manipulation using discrete actuator arrays". International Journal of Robotics Research. Vol. 20 No $^{\circ}$, pp. 553583. July, 2001.

[14] T. Murphey and J. Burdick. "Feedback control for distributed manipulation systems that involve mechanical contacts". International Journal of Robotics Research. Vol. $23 \mathrm{~N}^{\circ} 7$, pp. 763-781. July, 2004.
[15] P.U. Frei, M. Wiesendanger, R. Büchi and L. Ruf. "Simultaneous planar transport of multiple objects on individual trajectories using friction forces". In K.F. Böhringer and H. Choset, editors. Distributed Manipulation, pp. 49-64. Kluwer Academic Publishers. 2000.

[16] P. Czubak. "Equalization of the transport velocity in a new two-way vibratory conveyer". Archives of Civil and Mechanical Engineering. Vol. $11 \mathrm{~N}^{\circ}$ 3, pp. 573-586. 2011.

[17] J.E. Luntz, W Messner and H. Choset. "Parcel manipulation and dynamics with a distributed array: the virtual vehicle". IEEE Intern Conf on Robotics and Automation. Vol. 2, pp. 1541-1564. 1997. DOI: 10.1109/ ROBOT.1997.614359.

[18] D.S. Reznik. "The Universal Planar Manipulator". Ph. D. Thesis. University of California. 2000.

[19] E. Setter and I. Bucher. "Flexural vibration pattering using an array of actuators". Journal of Sound and Vibration. Vol. 330, pp. 11211140. 2011.

[20] A. Kamali and G.R. Vossoughhi. "A periodic solution for friction drive microrobots based on the iteration perturbation method". Scientia Iranica B. Vol. $18 \mathrm{~N}^{\mathrm{o}}$ 3, pp. 368-374. 2011.

[21] H. Patterson and B. Mcintyre. "Alimentador vibratorio". Oficina Española de Patentes y Marcas. España. ES 2217548 T3. 1998.

[22] Heathcote Industrial Plastics. "A guide to the use of composite leaf springs in vibration machinery", pp. 1-16. 2009. URL: www. heathcotes.com/Downloads/Spring $\% 20$ Manual.pdf 